\title{
The Design of a Novel Bearing Manufacturing Line Based on Simulation
}

\author{
Abeshek Ram Natarajan \\ Department of Mechanical Engineering, SSN College of Engineering, Chennai, India \\ Email: abeshek13001@mech.ssn.edu.in
}

How to cite this paper: Natarajan, A.R. (2016) The Design of a Novel Bearing Manufacturing Line Based on Simulation. American Journal of Operations Research, 6, 425-435.

http://dx.doi.org/10.4236/ajor.2016.66039

Received: September 15, 2016

Accepted: October 25, 2016

Published: October 28, 2016

Copyright $\odot 2016$ by author and Scientific Research Publishing Inc. This work is licensed under the Creative Commons Attribution International License (CC BY 4.0).

http://creativecommons.org/licenses/by/4.0/

\begin{abstract}
This paper is a case study of the production line at an automotive ancillary manufacturing plant. At first, the production line is studied for possible areas of improvement. Time study data are collected for each process and the best set-up is calculated to make the plant leaner. Furthermore, suggestions are made to procure machines from the market that make the plant leaner and more efficient. To make the suggestions indubitable, a time study calculation is done for the new machine layout.
\end{abstract}

\section{Keywords}

Production Line, Simulation, GPSS, Throughput

\section{Introduction}

Kaizen-Continuous improvement is the essence of successful manufacturing industries worldwide. There always exist some scopes for improvement in the company, hence efforts to improve should never be allowed to cease. The manufacturing industry is a major contributor to the growth of the Indian economy. Also, amongst the manufacturing industries, it is the automotive industry that contributes a larger percent. Despite having continued this trend for decades, the automotive industry still faces the difficulty of improving production. When the automotive industry is only predicted to grow from here, it is only obvious that its contribution to India's GDP will increase. However, this also means that the country's reliance on the industry will increase. Therefore, in this age of price competitiveness, it is important to avoid the company's profit slip due to the inability to produce parts on time. Hence, efficient balancing of the production line is of utmost importance. This paper uses simulation approach to effectively improve the output rate of the plant to satisfy the production goal of a bearing manufacturing company. 


\section{Literature Review}

This section reviews literature of simulation approach for improving the productivity of different production/service systems.

Panneerselvam and Veerapandian [1] considered the simulation of a season ticket issue counter of a transport organization at Chennai. They analyzed the behavior of male queues and female queues at different time intervals (one hour interval) from 3 P.M. to 8 P.M. and suggested to operate variable number of counters depending on the estimated queue length. The simulation logic has been implemented in FORTRAN language. Senthilkumar [2] developed an algorithm for multiple AGVS (Automated Guided Vehicle System) scheduling, which uses Floyd's algorithm as a subroutine to find the shortest distance between any pair of nodes in the distance network of the shop floor where the AGVs operate. This uses simulation approach to sample the demand points. The simulation logic has been implemented in Basic language. Panneerselvam and Senthilkumar [3] developed a text book titled 'System Simulation, Modeling and Languages', which presents several practical examples and case studies where the simulation approach can be used. The examples cover applications in shop floors and service systems using high level languages, GPSS (General Purpose Simulation System), Arena, etc, which is instrumental in understanding the use of GPSS. Gordon Geoffrey [4] and Jerry Banks [5] gave the concept of simulation and introduce different simulation languages. Furthermore, Panneerselvam [6] [7] gave a brief introduction to simulation and presented case studies which have been essential to learning the method of simulation. Moreover, Scriber [8] gave a complete account of GPSS covering all the blocks. Khalili and Zahedi [9] presented a simulation model for a mattress production line using Promodel simulation software. They analyzed the existing system and modified the system using simulation to cope with the demand of mattress for the next five years. Gingu and Zapciu [10] considered a layout design problem and obtained bottleneck locations using simulation to obtain a revised cellular layout.

The literature presented above justifies the need of simulation in industries and also presents foundations of the simulation approach. In this paper, the application of the simulation approach using GPSS to improve the throughput of a production line manufacturing a bearing is presented.

\section{Problem Identification}

The output of the line manufacturing an engine thrust bearing is unable to meet the demand of its customers. Moreover, the line supervisor is not convinced about the optimality of the lot size that is fixed while producing the bearing. The process times of different operations of the production line of the bearing are probabilistic. Hence, in this paper, an attempt has been made to simulate the production for the existing layout of the production line. After an analysis of the results about the average waiting time and average waiting number of jobs before different operations of the production line, another simulation model is to be constructed again to minimize the time taken which will improve the production volume of the line. 


\section{Data Collection}

This section presents data that are collected from the production line of the bearing (job). The inter-arrival time of the job to the first machine of the line follows uniform distribution with a mean of $6.79 \mathrm{sec}$ and a half width of $0.375 \mathrm{sec}$.

The different machines/operations of the production line manufacturing engine thrust bearings as per their sequence to manufacture that product are shown in Table 1. The processing time of each of the facilities shown in the Table 1 follows uniform distribution. The parameters of the uniform distribution of the processing times of the facilities are shown in Table 2. The block diagram of the facilities manufacturing the thrust bearing is shown in Figure 1.

Table 1. Machines/operations to manufacture engine thrust bearings.

\begin{tabular}{cc}
\hline Order of operation & Name of set up \\
\hline 1 & Blanking \\
2 & Deburring \\
3 & Flattening \\
4 & Grooving \\
5 & End-chamfer \\
6 & IDC \\
7 & ODC \\
8 & Grinding \\
9 & Vibro-finishing \\
10 & Flattening \\
11 & Washing \\
12 & Packing \\
\hline
\end{tabular}

Table 2. Processing times of facilities.

\begin{tabular}{ccc}
\hline \multirow{2}{*}{ Name of the facility } & \multicolumn{2}{c}{ Parameters of uniform distributions $(\mathrm{A} \pm \mathrm{B})$} \\
\cline { 2 - 3 } Blanking & Mean(seconds) & Half-width(seconds) \\
Deburring & 1.5 & \pm 0 \\
Flattening & 1.5 & \pm 0 \\
Grooving & 7 & \pm 0.2 \\
End-Chamfer & 5 & \pm 0.2 \\
IDC & 5 & \pm 1 \\
ODC & 9 & \pm 1 \\
Grinding & 10 & \pm 0.2 \\
Vibro-Finishing & 20 & \pm 1 \\
Flattening & 15 & \pm 0.2 \\
Washing & 2 & \pm 0.2 \\
Packing & 2 & \pm 0.5 \\
\hline
\end{tabular}



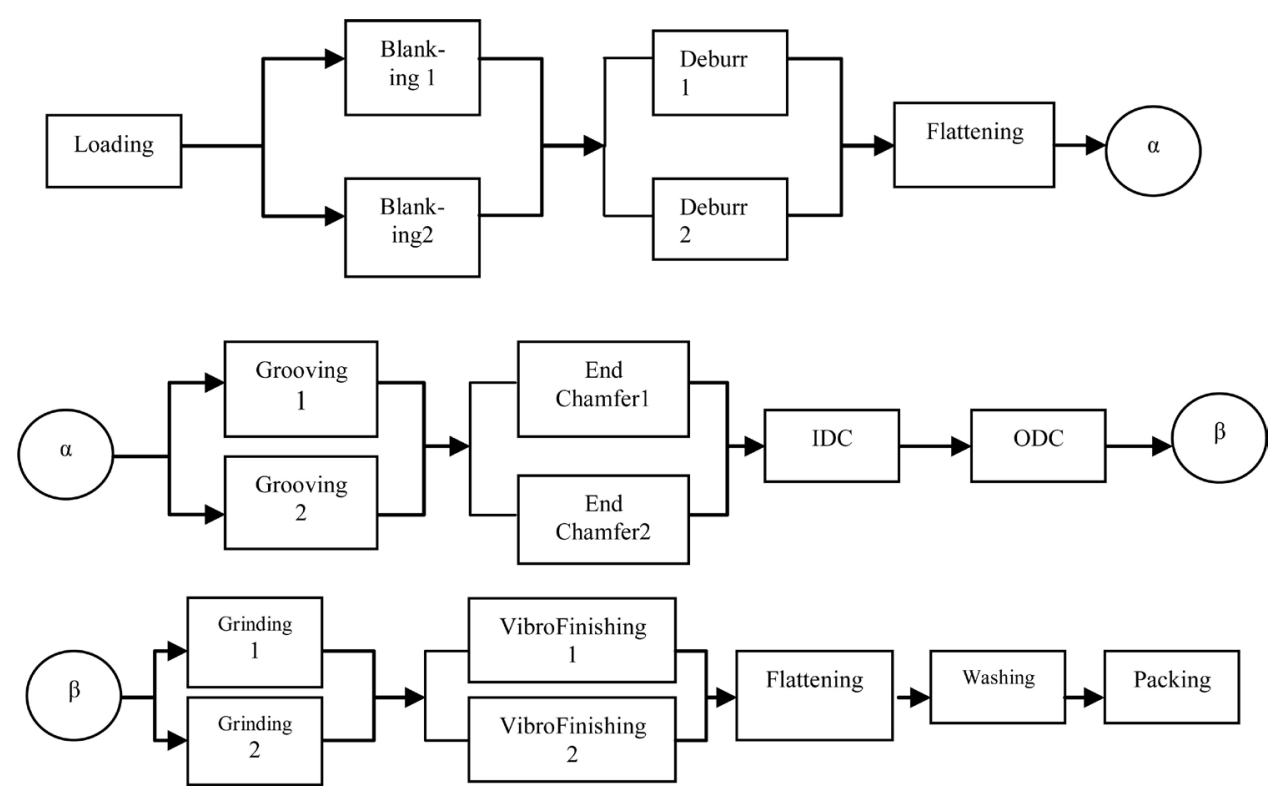

Figure 1. Block diagram of facilities manufacturing engine thrust bearings.

\section{GPSS Simulation Model for Existing System}

The inter-arrival time at the first operation of the bearing line as well as the processing time of each operation follows uniform distribution. Hence, use of empirical formula to obtain the standard results, viz. average waiting time of the job in front of each operation of the production line, the average waiting number of jobs bearings waiting in front of each operation of the production line and the percentage utilization of the operations, cannot be used. Therefore, the last resort to obtain such results of the production line is the use of simulation, which can provide these results. This section gives the simulation of the existing system whose particulars are shown in Table 1, Table 2 and Figure 1. The legends used in Figure 3 are shown in Figure 2. The GPSS block diagram to simulate production system considered in this paper is shown in Figure 3. The Figure 4 gives the timer segment. The corresponding GPSS program is shown in Figure 5. This contains the names of the GPSS blocks required to simulate the system shown in Figure 3. The simulation model is run for 80 hours, which is 288,000 seconds.

\section{Result of Simulation}

The execution of the GPSS program in Figure 5 gives these results for selected facilities and the corresponding queues are shown in Table 3 and Table 4. From Table 3, the number of transactions passing through the "packaging block", which corresponds to the last operation of the production line manufacturing the bearing, gives the production volume of the production line, which is 2870 units. From Table 4, it is clear that the maximum average waiting time per transaction is 1542.107 seconds for the facility "flattening". If the processing time for the operation on this facility is reduced by installing one more facility of the same type in parallel, the average waiting time per transition at this stage can be minimized. The next section discusses the improved system. 


\begin{tabular}{|c|c|}
\hline Symbols & Function \\
\hline GENERATE & Jobs are generated as per a defined probability distribution \\
\hline QUEUE & Adds the job into the queue \\
\hline ENTER & Makes an attempt to check whether at least one of the facilities is free \\
\hline DEPART & $\begin{array}{l}\text { When a facility becomes free, the job moves from the queue and enters the facility for } \\
\text { service }\end{array}$ \\
\hline ADVANCE & Increments the clock time by the service time required for the job \\
\hline LEAVE & Frees a facility our of parallel servers \\
\hline SEIZE & Makes an attempt to capture the facility for a job to be done \\
\hline RELEASE & Makes an attempt to free the facility after job is done \\
\hline & Adds a customer into the queue \\
\hline & Removes a customer from a the queue \\
\hline & Connector of flow chart \\
\hline TERN & Sends the job out of the production line \\
\hline
\end{tabular}

Figure 2. Legend for the given flowchart
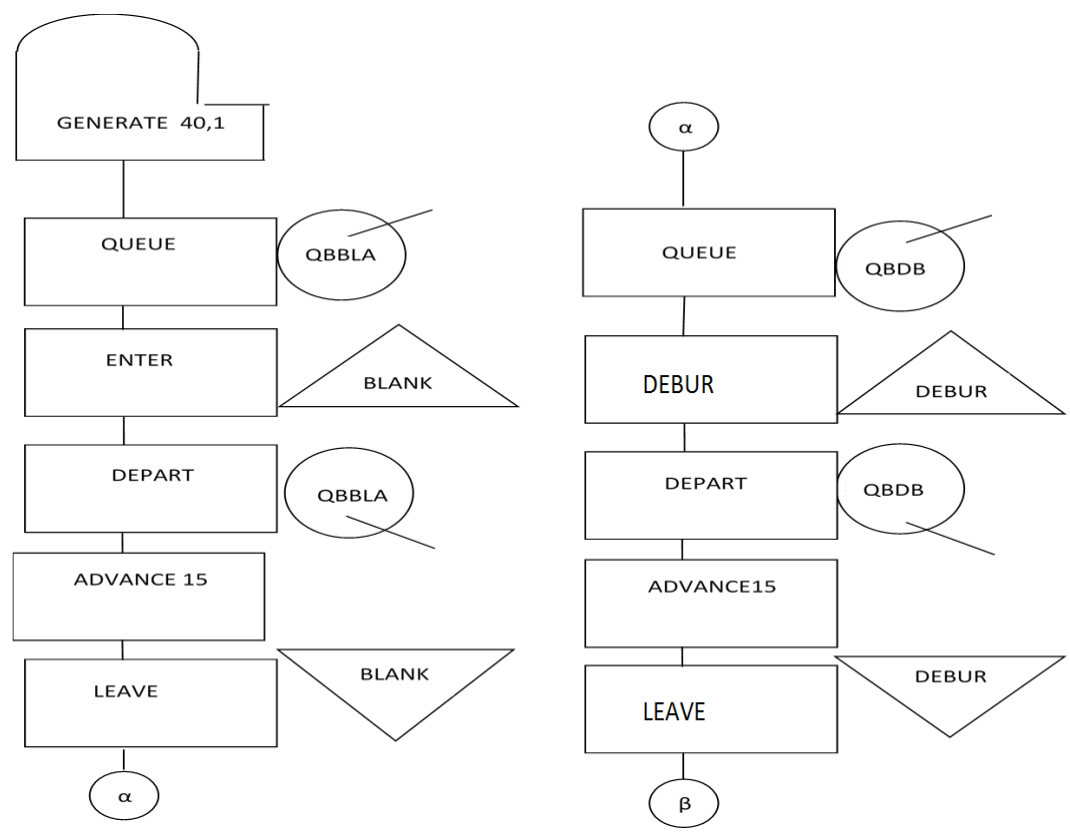

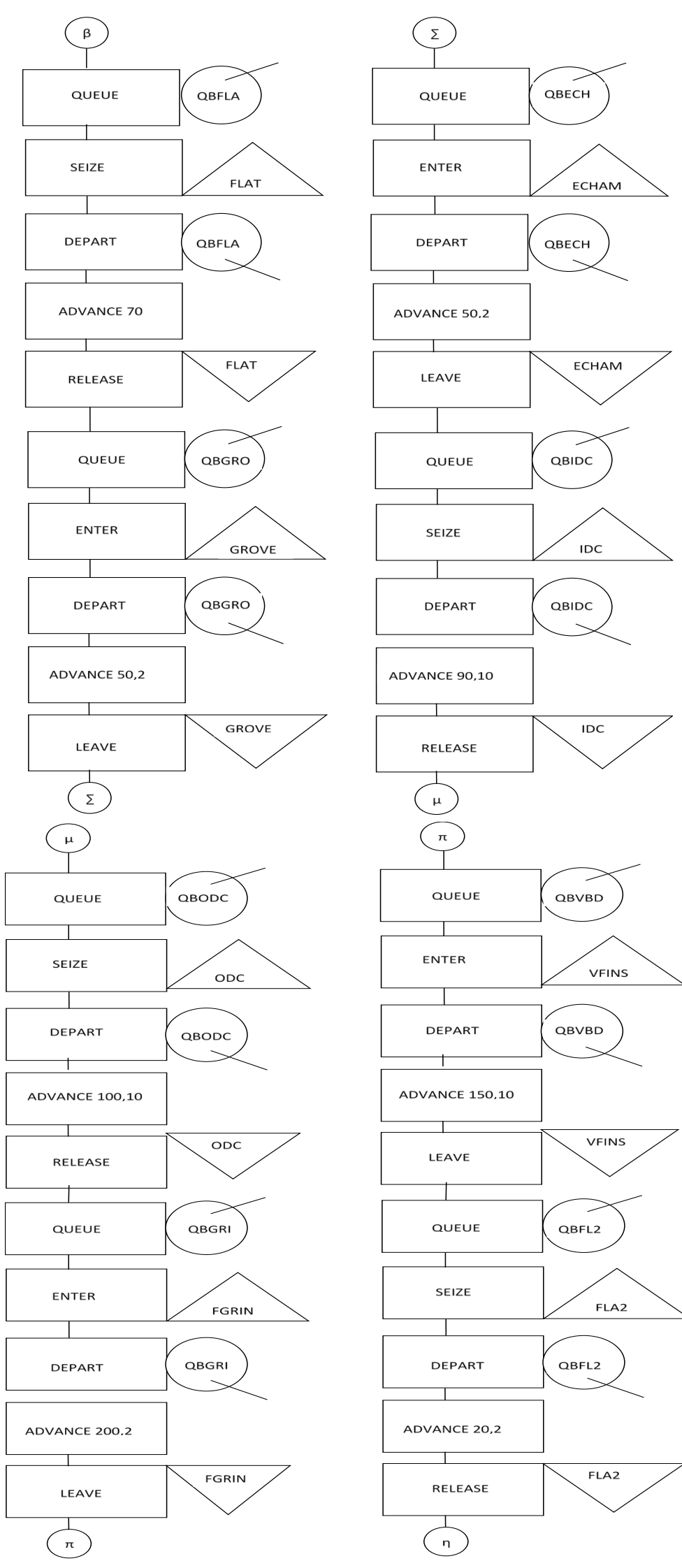

(u)

$\pi$
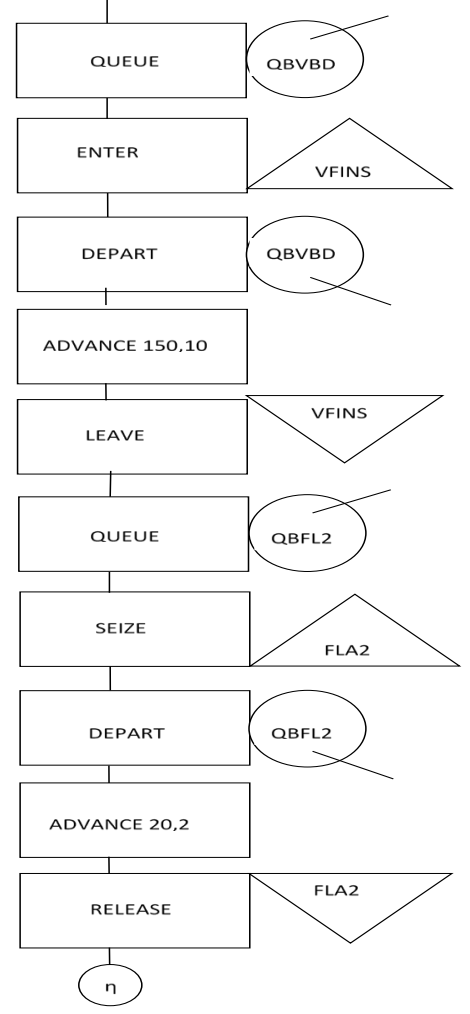

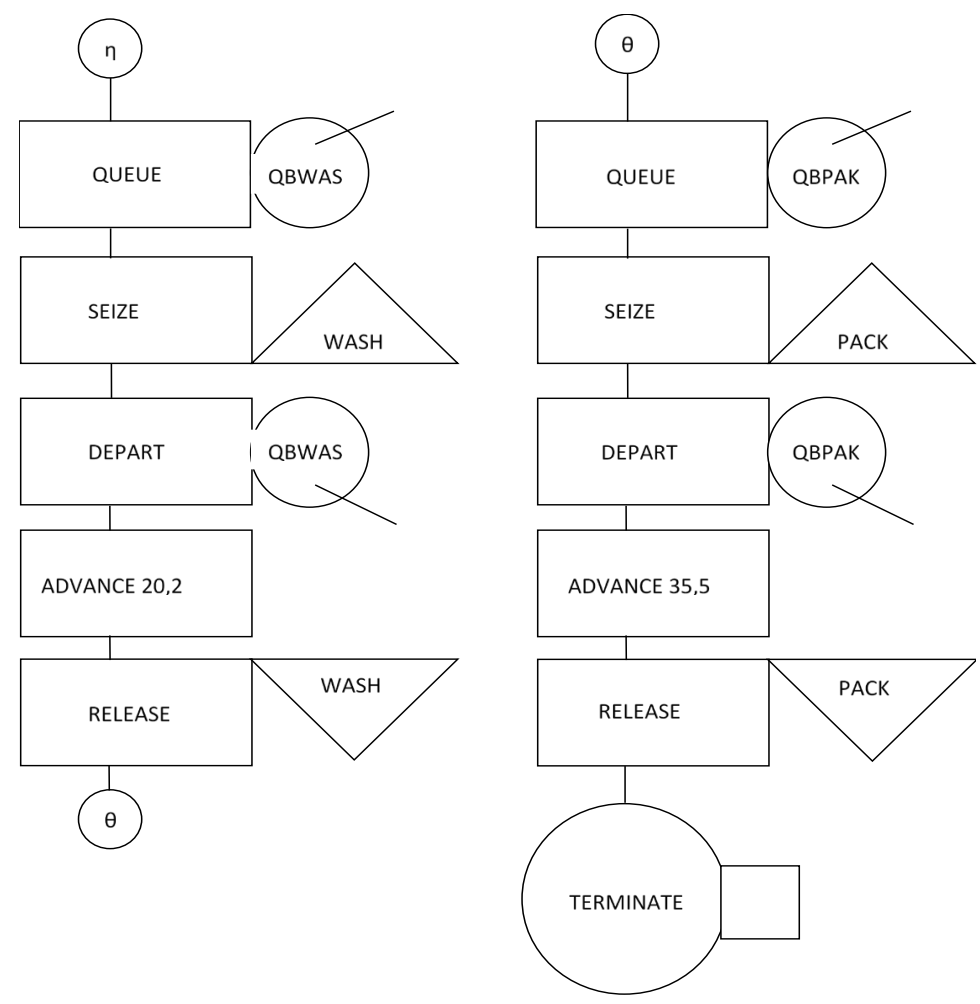

Figure 3. Main model segment.

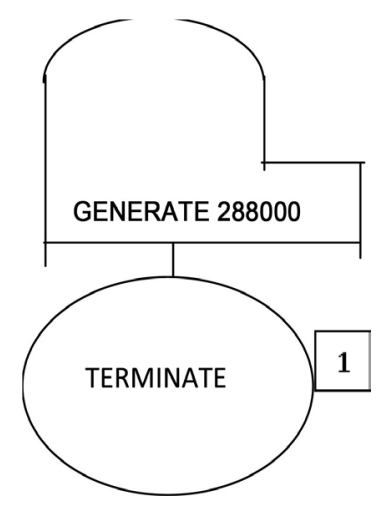

Figure 4. Timer diagram.

\section{Simulation of an Improved System}

The revised block diagram of the production line after incorporating a parallel facility for the first "flattening" stage is shown in Figure 6. The GPSS program for the revised system is shown in Figure 7. The execution of the GPSS program shown in Figure 7 gives the results for selected facilities and the corresponding queues are shown in Table 5 and Table 6. From Table 5, the number of transactions passing through the "packaging block", which corresponds to the last operation of the production line manufacturing the bearing, gives the production volume of the production line, which is 6377 units. From Table 6, it is clear that the maximum average waiting time per transaction is 390.479 seconds for the facility 'ID chamfering'. The revised design of the line manu- 


\begin{tabular}{|c|c|c|c|c|c|}
\hline 1 BLANK & STORAGE & 2 & 36 & ADVANCE & 90,10 \\
\hline 2 DEBUR & STORAGE & 2 & 37 & RELEASE & IDC \\
\hline 3 GROVE & STORAGE & 2 & 38 & QUEUE & QBODC \\
\hline 4 ECHAM & STORAGE & 2 & 39 & SEIZE & ODC \\
\hline 5 FGRIN & STORAGE & 2 & 40 & DEPART & QBODC \\
\hline 6 VFINS & STORAGE & 2 & 41 & ADVANCE & 100,10 \\
\hline 7 & GENERATE & 40 & 42 & RELEASE & ODC \\
\hline 8 & QUEUE & QBBLA & 43 & QUEUE & QBGRI \\
\hline 9 & ENTER & BLANK & 44 & ENTER & FGRIN \\
\hline 10 & DEPART & QBBLA & 45 & DEPART & QBGRI \\
\hline 11 & ADVANCE & 15 & 46 & ADVANCE & 200,2 \\
\hline 12 & LEAVE & BLANK & 47 & LEAVE & FGRIN \\
\hline 13 & QUEUE & QBDB & 48 & QUEUE & QBVBD \\
\hline 14 & ENTER & DEBUR & 49 & ENTER & VFINS \\
\hline 15 & DEPART & QBDB & 50 & DEPART & QBVBD \\
\hline 16 & ADVANCE & 15 & 51 & ADVANCE & 150,10 \\
\hline 17 & LEAVE & DEBUR & 52 & LEAVE & VFINS \\
\hline 18 & QUEUE & QBFLA & 53 & QUEUE & QBFL2 \\
\hline 19 & SEIZE & FLAT & 54 & SEIZE & FLA2 \\
\hline 20 & DEPART & QBFLA & 55 & DEPART & QBFL2 \\
\hline 21 & ADVANCE & 70 & 56 & ADVANCE & 20,2 \\
\hline 22 & RELEASE & FLAT & 57 & RELEASE & FLA2 \\
\hline 23 & QUEUE & QBGRO & 58 & QUEUE & QBWAS \\
\hline 24 & ENTER & GROVE & 59 & SEIZE & WASH \\
\hline 25 & DEPART & QBGRO & 60 & DEPART & QBWAS \\
\hline 26 & ADVANCE & 50,2 & 61 & ADVANCE & 20,2 \\
\hline 27 & LEAVE & GROVE & 62 & RELEASE & WASH \\
\hline 28 & QUEUE & QBECH & 63 & QUEUE & QBPAK \\
\hline 29 & ENTER & ECHAM & 64 & SEIZE & PACK \\
\hline 30 & DEPART & QBECH & 65 & DEPART & QBPAK \\
\hline 31 & ADVANCE & 50,2 & 66 & ADVANCE & 35,5 \\
\hline 32 & LEAVE & ECHAM & 67 & RELEASE & PACK \\
\hline 33 & QUEUE & QBIDC & 68 & TERMINATE & \\
\hline 34 & SEIZE & IDC & 69 & GENERATE & 288000 \\
\hline 35 & DEPART & QBIDC & 70 & TERMINATE & 1 \\
\hline
\end{tabular}

Figure 5. GPSS program to simulate system shown in Figure 3.

Table 3. Results of facilities.

\begin{tabular}{cccc}
\hline Name of facility/storage & Number of storages & $\begin{array}{c}\text { Number of transactions } \\
\text { through facility }\end{array}$ & Percentage utilization \\
\hline Blanking & 2 & 7199 & 18.70 \\
Deburring & 2 & 7199 & 18.70 \\
Flattening & 1 & 4114 & 100.00 \\
Grooving & 2 & 4113 & 35.70 \\
End-Chamfering & 2 & 4112 & 35.70 \\
IDC & 1 & 3203 & 99.99 \\
ODC & 1 & 2887 & 99.99 \\
Grinding & 2 & 2874 & 99.80 \\
Vibro-finishing & 2 & 2872 & 74.80 \\
Flattening & 1 & 2872 & 19.99 \\
Washing & 1 & 2871 & 19.99 \\
Packing & 1 & 2871 & 34.80 \\
\hline
\end{tabular}


Table 4. Results of queues.

\begin{tabular}{ccc}
\hline Name of queue & Average number of waiting jobs & Average waiting time(seconds) \\
\hline Blanking & 0 & 0.000 \\
Deburring & 0 & 0.000 \\
Flattening & 3085 & 1542.107 \\
Grooving & 0 & 0.000 \\
End chamfering & 0 & 0.000 \\
ID Chamfering & 908 & 453.756 \\
OD Chamfering & 325 & 162.347 \\
Grinding & 2 & 1.171 \\
Vibro-finishing & 0 & 0.000 \\
Flattening 2 & 0 & 0.000 \\
Washing & 0 & 0.000 \\
Packing & 0 & 0.000 \\
\hline
\end{tabular}
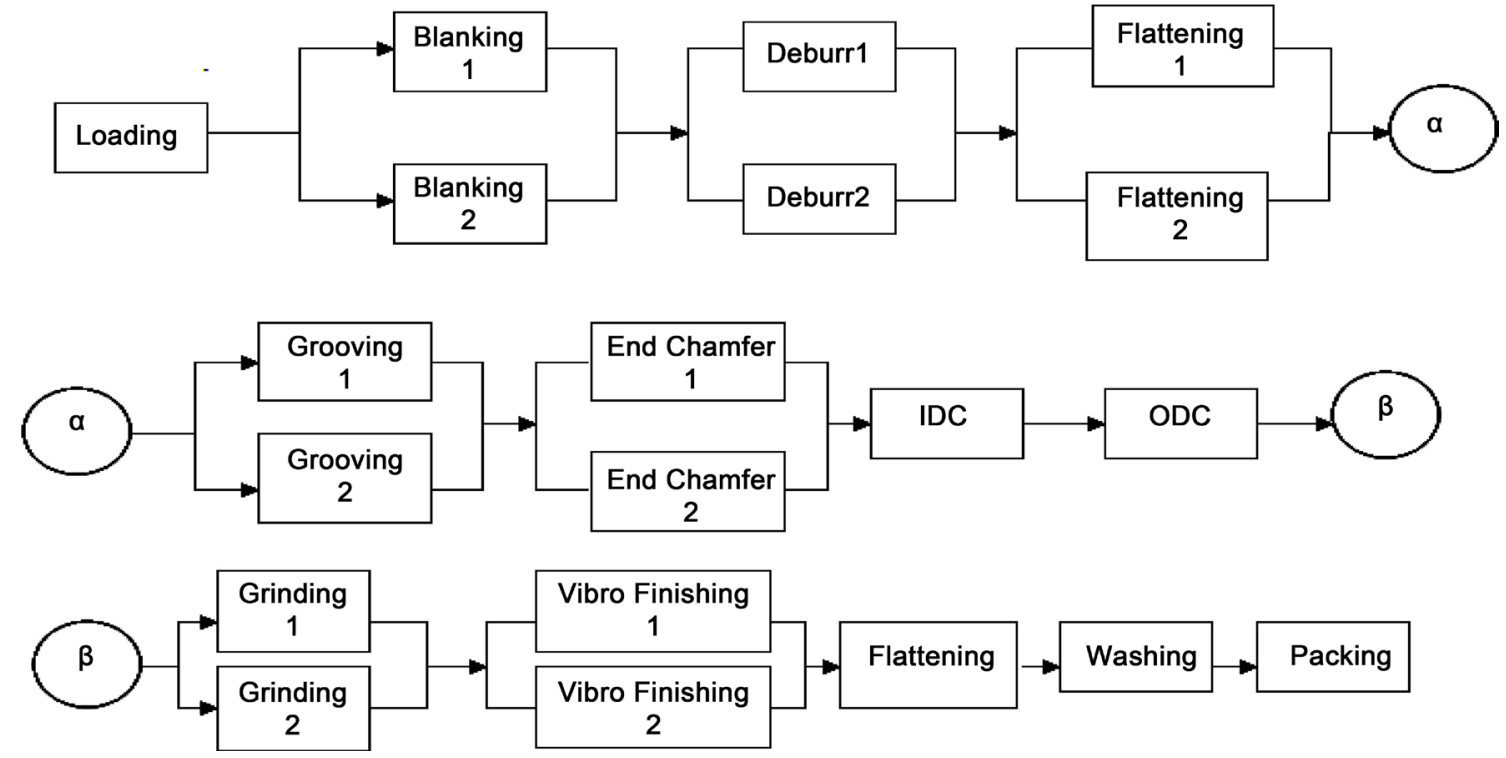

Figure 6. Improved Block diagram of facilities manufacturing engine thrust bearings.

facturing the bearing gives a tremendous improvement in the production volume from 2870 units to 6377 units.

\section{Conclusion}

The productivity is the key concern of any manufacturing system. In this particular line which manufactures the engine thrust bearing, the existing production volume is very low. Hence, in this paper, in the first phase, the existing system has been simulated to find the critical operation(s). Then, the existing system of production of the bearing has been modified based on the suggestions of the first phase of this study. Then the revised 


\begin{tabular}{|c|c|c|c|c|c|}
\hline 1 BLANK & STORAGE & 2 & 37 & RELEASE & IDC \\
\hline 2 DEBUR & STORAGE & 2 & 38 & QUEUE & QBODC \\
\hline 3 GROVE & STORAGE & 2 & 39 & SEIZE & ODC \\
\hline 4 ECHAM & STORAGE & 2 & 40 & DEPART & QBODC \\
\hline 5 FGRIN & STORAGE & 2 & 41 & ADVANCE & 45,10 \\
\hline 6 VFINS & STORAGE & 2 & 42 & RELEASE & ODC \\
\hline 6.5 FLAT & STORAGE & 2 & 43 & QUEUE & QBGRI \\
\hline 7 & GENERATE & 40 & 44 & ENTER & FGRIN \\
\hline 8 & QUEUE & QBBLA & 45 & DEPART & QBGRI \\
\hline 9 & ENTER & BLANK & 46 & ADVANCE & 60,10 \\
\hline 10 & DEPART & QBBLA & 47 & LEAVE & FGRIN \\
\hline 11 & ADVANCE & 15 & 48 & QUEUE & QBVBD \\
\hline 12 & LEAVE & BLANK & 49 & ENTER & VFINS \\
\hline 13 & QUEUE & QBDB & 50 & DEPART & QBVBD \\
\hline 14 & ENTER & DEBUR & 51 & ADVANCE & 60,10 \\
\hline 15 & DEPART & QBDB & 52 & LEAVE & VFINS \\
\hline 16 & ADVANCE & 15 & 53 & QUEUE & QBFL2 \\
\hline 17 & LEAVE & DEBUR & 54 & SEIZE & FLA2 \\
\hline 18 & QUEUE & QBFLA & 55 & DEPART & QBFL2 \\
\hline 19 & ENTER & FLAT & 56 & ADVANCE & 20,2 \\
\hline 20 & DEPART & QBFLA & 57 & RELEASE & FLA2 \\
\hline 21 & ADVANCE & 40 & 58 & QUEUE & QBWAS \\
\hline 22 & LEAVE & FLAT & 59 & SEIZE & WASH \\
\hline 23 & QUEUE & QBGRO & 60 & DEPART & QBWAS \\
\hline 24 & ENTER & GROVE & 61 & ADVANCE & 20,2 \\
\hline 25 & DEPART & QBGRO & 62 & RELEASE & WASH \\
\hline 26 & ADVANCE & 50,2 & 63 & QUEUE & QBPAK \\
\hline 27 & LEAVE & GROVE & 64 & SEIZE & PACK \\
\hline 28 & QUEUE & QBECH & 65 & DEPART & QBPAK \\
\hline 29 & ENTER & ECHAM & 66 & ADVANCE & 35,5 \\
\hline 30 & DEPART & QBECH & 67 & RELEASE & PACK \\
\hline 31 & ADVANCE & 50,2 & 68 & TERMINATE & \\
\hline 32 & LEAVE & ECHAM & 69 & GENERATE & 288000 \\
\hline 33 & QUEUE & QBIDC & 70 & TERMINATE & 1 \\
\hline 34 & SEIZE & IDC & & & \\
\hline 35 & DEPART & QBIDC & & & \\
\hline 36 & ADVANCE & 45,10 & & & \\
\hline
\end{tabular}

Figure 7. GPSS program for improved system involving adding of new IDC, ODC, Grinding, and Vibro-finishing machines.

Table 5. Results of facilities.

\begin{tabular}{cccc}
\hline Name of facility/storage & Number of storages & $\begin{array}{c}\text { Number of transactions } \\
\text { through facility }\end{array}$ & Percentage utilization \\
\hline Blanking & 2 & 7200 & 18.70 \\
Deburring & 2 & 7199 & 18.70 \\
Flattening & 2 & 7199 & 50.00 \\
Grooving & 2 & 7198 & 62.50 \\
End Chamfering & 2 & 7196 & 62.50 \\
IDC & 1 & 6412 & 99.99 \\
ODC & 1 & 6383 & 99.99 \\
Grinding & 2 & 6382 & 66.50 \\
Vibro-finishing & 2 & 6380 & 66.50 \\
Flattening & 1 & 6379 & 44.3 \\
Washing & 1 & 6378 & 44.3 \\
Packing & 1 & 6378 & 77.5 \\
\hline
\end{tabular}


Table 6. Results of queues.

\begin{tabular}{ccc}
\hline Name of queue & Average number of waiting jobs & Average waiting time (seconds) \\
\hline Blanking & 0 & 0.000 \\
Deburring & 0 & 0.000 \\
Flattening & 0 & 0.000 \\
Grooving & 0 & 0.000 \\
End chamfering & 0 & 0.000 \\
ID Chamfering & 783 & 390.479 \\
OD Chamfering & 28 & 16.439 \\
Grinding & 0 & 0.000 \\
Vibro-finishing & 0 & 0.001 \\
Flattening 2 & 0 & 0.002 \\
Washing & 0 & 0.000 \\
Packing & 0 & 0.043 \\
\hline
\end{tabular}

model has been simulated and it is found that the revised model gives tremendous improvement in the production volume for the engine thrust bearing line.

\section{Acknowledgements}

I thank the anonymous referees for their constructive suggestions, which helped me to improve the paper.

\section{References}

[1] Panneerselvam, R. and Veerapandian, M. (1990) Simulation of a Season Ticket Issue Counter of a Transport Corporation. Industrial Engineering Journal, 19, 21-25.

[2] Senthilkumar, P., Damodaran, K.M. and Panneerselvam, R. (2003) Algorithm for Multiple AGVS Scheduling. Industrial Engineering Journal, 32, 20-26.

[3] Panneerselvam, R. and Senthilkumar, P. (2013) System Simulation, Modeling and Languages. PHI Learning Private Limited, New Delhi.

[4] Geoffrey, G. (1978) System Simulation. 2nd Edition, Prentice-Hall, Englewood Cliffs.

[5] Banks, J., Carson, J.S., Nelson, B.L. and Nicol, D.M. (2010) Discrete-Event System Simulation. 5th Edition, Pearson Education, New Delhi.

[6] Panneerselvam, R. (2004) Research Methodology. PHI Learning, New Delhi.

[7] Panneerselvam, R. (2006) Operations Research. 2nd Edition, PHI Learning, New Delhi.

[8] Scriber, T.J. (1974) Simulation Using GPSS. John Wiley \& Sons, New York.

[9] Khalili, H.H. and Zahedi, F (2013) Modeling and Simulation of Mattress Production Line Using Promodel. Proceedings of the 2013 Winter Simulation Conference: Simulation: Making in a Complex World, Washington DC, 8-11 December 2013, 2598-2909. http://dx.doi.org/10.1109/WSC.2013.6721632

[10] Gingu, E.L. and Zapciu, M. (2014) Improving Layout and Workload of Manufacturing System Using Delmia Quest Simulation and Inventory Approach. International Journal of Innovative Research in Advanced Engineering, 1, 52-61. 
Submit or recommend next manuscript to SCIRP and we will provide best service for you:

Accepting pre-submission inquiries through Email, Facebook, LinkedIn, Twitter, etc. A wide selection of journals (inclusive of 9 subjects, more than 200 journals)

Providing 24-hour high-quality service

User-friendly online submission system

Fair and swift peer-review system

Efficient typesetting and proofreading procedure

Display of the result of downloads and visits, as well as the number of cited articles

Maximum dissemination of your research work

Submit your manuscript at: http://papersubmission.scirp.org/

Or contact ajor@scirp.org 